\title{
WITH A LITTLE HELP FROM MY CUSTOMERS: THE INFLUENCE OF CUSTOMER EMPOWERMENT ON CONSUMERS' PERCEPTIONS OF WELL-ESTABLISHED BRANDS
}

\author{
MARTIN MEIßNER \\ Department of Environmental and Business Economics \\ University of Southern Denmark \\ Niels Bohrs Vej 9-10, 6700 Esbjerg, Denmark \\ Department of Marketing, Monash University \\ Level 7, S Building, Sir John Monash Drive \\ Caulfield Vic 3145, Australia \\ MICHELLE D. HAURAND \\ Department of Business Administration and Economics \\ Bielefeld University, Universitätsstr. 25, 33615 Bielefeld, Germany \\ CHRISTIAN STUMMER* \\ Department of Business Administration and Economics \\ Bielefeld University, Universitätsstr. 25, 33615 Bielefeld, Germany \\ christian.stummer@uni-bielefeld.de \\ Published 20 February 2017
}

\begin{abstract}
Labelling product innovations as designed and/or selected by customers can positively affect non-participating consumers' self-stated behavioural intentions, that is, it can increase the probability of purchasing that product. Most previous studies have used fictitious brands to test the aforementioned effect, raising concerns about the degree to which these findings are relevant for marketing practice. Brand managers thus might wonder whether labelling product innovations as user-designed and/or user-selected might indeed increase sales for their well-established brands. This paper addresses this research gap by
\end{abstract}

\footnotetext{
*Corresponding author.
}

This is an Open Access article published by World Scientific Publishing Company. It is distributed under the terms of the Creative Commons Attribution 4.0 (CC-BY-NC) License. Further distribution of this work is permitted, provided the original work is properly cited. 
investigating the possible effects of three alternative strategies for labelling innovations (i.e., empowerment-to-select, empowerment-to-create, and full empowerment) for two well-established technology brands. For all three strategies and both brands, we find that involving customers significantly increases the perceived innovation ability, which then positively mediates the effect on behavioural intentions. However, due to a negative direct effect, only labelling products as selected by customers has an overall positive effect.

Keywords: Labelling innovations; empowerment-to-select; empowerment-to-create; wellestablished brands; technology brands.

\section{Introduction}

The involvement of customers in the process of new product development has received considerable interest, both from researchers and from practitioners as brand managers have sought to better understand the circumstances under which it is advisable to empower customers in the innovation process. This increased interest is fuelled by reports from companies that have already successfully developed and marketed innovative products designed by customers. Muji, an established Japanese manufacturer of a broad range of consumer goods, may serve as an illustrative example. For this case, Nishikawa et al. (2013) have shown that customer-generated products outperform their designer-generated counterparts in terms of sales revenues, which suggests that customer empowerment pays off financially in the long run. In an even more recent study, Nishikawa et al. (2017) underscored that the positive effect of customer empowerment on sales does not necessarily need to stem from an improved product; labelling products as "customer-ideated" also leads to better market performance due to consumers' perceptions of the products.

To better explain the observed effects on sales resulting from labelling products as "customer-ideated," Schreier et al. (2012) developed the theoretical framework of perceived customer empowerment. The authors suggested that empowering customers changes the perceived ability of a firm to innovate, which then also positively affects the behavioural intentions of consumers. ${ }^{1}$ Based on several empirical studies, Schreier et al. provide strong evidence that perceived innovation ability indeed positively mediates the effect that customer empowerment has on the intended purchase behaviour. Because their mediation analysis was based

\footnotetext{
${ }^{1}$ While those who are empowered by a company are usually customers of their brand (and are referred to as such throughout this paper), there are also uninvolved people observing this interaction between the customers and the company, who could be - but do not necessarily need to be (potential) customers. To avoid any confusion between these two groups, the latter are called consumers in this paper.
} 
on theoretical considerations (further explained in the hypothesis development part of our paper), we think that there is valid evidence for the suggested effect. An important restriction of earlier empirical studies conducted under this theoretical framework, however, is that these studies mostly tested fictitious brands (an overview of these studies can be found in the third section). We believe that testing the effect for well-established brands is of particular practical relevance, because marketing managers should - if the effects persist - indeed empower their customers and use that information to market their products. In an earlier paper, Fuchs and Schreier (2011) highlighted the limitations of their empirical findings for marketing practice by stating that they "cannot make any corroborated claims as to the consequences of customer empowerment for established brands" (p. 29). To the best of our knowledge, only three articles (Fuchs et al., 2013; Van Dijk et al., 2014; Nishikawa et al., 2017) have tested real brands from three product categories (fashion, (simple) electronics, and food) in the framework of perceived customer empowerment. This lack of empirical evidence regarding the effect on established brands drives the central aim of our work, to validate this theoretical framework by investigating well-established brands empowering their customers. To achieve this goal, we address the following three research questions:

- How does customer empowerment affect the perceived innovation ability of well-established brands?

- How does customer empowerment affect the behavioural intentions towards well-established brands?

- How does the potential effect on the perceived innovation ability and on behavioural intentions differ for alternative empowerment strategies used for labelling innovations?

It is important to emphasise that we use self-reported behavioural intentions instead of actual market data in this paper because we want to test the key mediation mechanism, which requires asking consumers about their perception of the innovation ability of the respective company. Moreover, conducting field experiments is difficult, as only few companies are willing to jeopardise their actual sales by attaching a potentially negative label to their products (for further argumentation as well as an exception to this, see, e.g., Nishikawa et al., 2017).

The research contribution of our paper is thus twofold. First, we test whether positive effects on non-involved consumers' perceptions also apply for wellestablished brands. For this purpose, we consider smartphones to be a particularly interesting product category, as it has been shown that consumers use smartphone brands, especially Apple products, to signal high status (Ferraro et al., 2013). Thus, the potential effects will be tested in a product category in which the brand is 
supposed to influence the purchase process of many consumers in order to see whether a positive effect on the perceived innovation ability and behavioural intentions can still be found. The second key contribution of our paper lies in testing four alternative strategies for labelling innovations of actual existing brands: zero empowerment, empowerment-to-create, empowerment-to-select, and full empowerment, all of which are elaborated upon in the following section.

The remainder of the paper is structured as follows: The second section provides a short overview of different aspects of customer empowerment. In the third section, we review previous empirical studies that have investigated the effects of customer empowerment on non-involved consumers. As our focus lies on papers investigating the perception of products manufactured by empowering companies, we are not concerned with the subjective experience or outcome of empowerment (Wathieu et al., 2002), individuals' motivation to share knowledge (Kosonen et al., 2014), or the use of different communication channels in the process of customer empowerment (Jespersen, 2011). The findings provide a foundation for deriving the research hypotheses in the fourth section. The design of our empirical study is described in the fifth section and key results are presented and discussed in the sixth section. In the final section, the paper concludes with a summary, an examination of remaining limitations, and an outlook on promising directions for further research.

\section{The Effect of Customer Empowerment on Non-Involved Consumers}

Customer empowerment has been defined as a "process in which [companies and customers] systematically interact, learn, share information and integrate resources to jointly create value" (Van Dijk et al., 2014, p. 110). Today's easy access to information and customers' ability to communicate among themselves provide ordinary customers with a sense of empowerment and/or a desire to play a greater role in exchanging ideas with companies (Hoyer et al., 2010). Besides better financial results, researchers have found several positive effects of empowerment efforts on participating customers. It has been shown, for example, that customer empowerment might lead to more customer acceptance of a new product (Mahr et al., 2014) and a considerably increased willingness to pay for self-designed products (Franke and Piller, 2004). However, the success and merit of any empowerment effort likely varies by industry and product category (Poetz and Schreier, 2012).

From a managerial perspective, the spread of the empowerment idea has also largely changed the way in which companies think about their customers. 
Previously, customers were regarded primarily as a passive source of income; today they are also recognised as active suppliers of value creation (Ramaswamy and Gouillart, 2010) who help companies to better identify consumers' needs and desires and - even more importantly - translate these needs into concrete product ideas (Kaplan and Haenlein, 2006; Zipkin, 2001). Under this new paradigm, customers become a potential source of competence and thus of competitive advantage to a company (Prahalad and Ramaswamy, 2000).

The empowerment of customers has not only enriched the new product development process but has also been shown to affect the perception of non-involved consumers with respect to the company and its products. The first empirical studies concerning non-involved consumers, conducted by Fuchs and Schreier (2011), revealed that customer empowerment leads to more favourable attitudes and more positive behavioural intentions towards companies that involve their customers in the product development process. Their work can be considered as "an important shift in thinking" in the field of customer empowerment (Gemser and Perks, 2015, p. 660) because it takes into account that products can be marketed as originating from an empowering company. Gemser and Perks therefore highlighted this paper in their editorial issue as one of the first articles to include empirical studies with a focus on the perception of empowering companies.

Moreover, Fuchs and Schreier (2011) suggested that customers may be empowered in multiple ways, that is, in the creation stage, the selection stage, or both stages of the new product development process (an overview is provided in Table 1). An empowerment strategy that involves customers in the first but not in the second stage is called an empowerment-to-create (CE) strategy. With this strategy, the company keeps control of the process of selecting the product to be introduced into mass production. If customers remain uninvolved at the first stage but are empowered to select one or more new products to be produced by the company, an empowerment-to-select (SE) strategy is applied. Alternatively, the company may also decide to involve customers in both the creation and selection stage, which is called fall empowerment (FE). In our empirical study, we test all three empowerment strategies [as well as a condition in which customers are not involved at all, which is labelled zero empowerment (ZE)].

Table 1. Classification of empowerment strategies following Fuchs and Schreier (2011).

\begin{tabular}{cccc}
\hline & & \multicolumn{2}{c}{ Who selects between new product designs? } \\
\cline { 3 - 4 } & & Company & Customers \\
\hline $\begin{array}{c}\text { Who creates new product } \\
\text { designs? }\end{array}$ & $\begin{array}{c}\text { Company } \\
\text { Customers }\end{array}$ & $\begin{array}{c}\text { Zero empowerment } \\
\text { Empowerment-to-create }\end{array}$ & $\begin{array}{c}\text { Empowerment-to-select } \\
\text { Full empowerment }\end{array}$ \\
\hline
\end{tabular}


Table 2. Previous empirical studies concerning the effect of empowerment on non-involved consumers.

\begin{tabular}{|c|c|c|c|}
\hline Study & Product category & $\begin{array}{l}\text { Fictitious versus well- } \\
\text { established brand tested }\end{array}$ & $\begin{array}{l}\text { Empowerment } \\
\text { strategy tested }\end{array}$ \\
\hline $\begin{array}{l}\text { Fuchs and Schreier } \\
\qquad \text { (2011) }\end{array}$ & T-shirts, furniture, bicycles & $\begin{array}{l}\text { Brand kept blind or } \\
\text { unknown to } \\
\text { respondents }\end{array}$ & SE, CE, FE \\
\hline $\begin{array}{l}\text { Schreier et al. } \\
\text { (2012) }\end{array}$ & $\begin{array}{l}\text { Cereal, T-shirts, household } \\
\text { products, outdoor } \\
\text { equipment, consumer } \\
\text { electronics, electric/ } \\
\text { mechanical gardening } \\
\text { products, robotic toys }\end{array}$ & $\begin{array}{l}\text { Brands kept blind in all } \\
\text { four studies }\end{array}$ & $\mathrm{CE}$ \\
\hline Fuchs et al. (2013) & Luxury fashion brands & $\begin{array}{l}\text { Explicit brand information } \\
\text { in all four studies. } \\
\text { Tested factor: luxury } \\
\text { brands versus } \\
\text { mainstream brands }\end{array}$ & $\mathrm{CE}, \mathrm{SE}$ \\
\hline $\begin{array}{l}\text { Van Dijk et al. } \\
\text { (2014) }\end{array}$ & Tapas & $\begin{array}{l}\text { Well-established brand } \\
\text { versus fictitious brand } \\
\text { tested }\end{array}$ & $\mathrm{CE}$ \\
\hline Dahl et al. (2015) & T-shirts, cereals, software & $\begin{array}{l}\text { Brands kept blind in all } \\
\text { three studies }\end{array}$ & $\mathrm{CE}$ \\
\hline $\begin{array}{l}\text { Nishikawa et al. } \\
\text { (2017) }\end{array}$ & Snacks, (simple) electronics & Brand partially kept blind & $\mathrm{CE}$ \\
\hline
\end{tabular}

Fuchs and Schreier (2011) work was the first to empirically address how companies that label products as customer designed are perceived by regular consumers. Building on their paper, further studies have continued this stream of research; an overview is provided in Table 2.

It is particularly noteworthy that only the papers by Fuchs et al. (2013), Van Dijk et al. (2014), and Nishikawa et al. (2017) tested real brands. Moreover, only one study tested the FE strategy and only two studies tested the SE strategy. In line with our three main research questions, we describe findings of previous studies with respect to two study characteristics - fictitious versus well-established brand tested and empowerment strategy tested — in the following.

\section{Fictitious versus well-established/real brand}

The studies by Fuchs and Schreier (2011), Schreier et al. (2012), and Dahl et al. (2015) kept the brand information blind or respondents rated fictitious brands. Although excluding potential branding effects may help to generalise findings, it 
also renders results less applicable given that branding plays a major role in many real-life purchasing decisions.

The studies presented in Fuchs et al. (2013) are a notable exception because they test potential effects for well-known luxury and mainstream fashion brands. The results of their studies showed that customer-design can also have negative effects on behavioural intentions for luxury brands. At the same time, they found positive effects for non-luxury fashion brands. The authors explained the observed difference with the high status-relevance of the product category "luxury fashion". Building on the psychological literature on social distance and comparison, they argued that consumers use luxury fashion brands to distance themselves from other consumers. High-fashion brands are positioned as exclusive brands for a wealthy consumer segment. Because status is a fundamental component of social comparison, high status products are used by consumers to "signal a high rank in society and, consequently, to have high status" (Fuchs et al., 2013, p. 78). The authors also claimed that luxury fashion evokes agentic feelings (i.e., feelings of advantage, superiority, and worth) when wearing the respective brands and influences the perception of design quality. Fashion brands designed by customers (instead of star designers) therefore lose their ability to signal high status and thus the consumers' behavioural intentions decrease unless either the importance of status is lowered or the design of the customers is justified (through legitimised status conferred by the chief designer or by being artists or celebrities). This effect has led to the conclusion that customer design "backfires" in the context of luxury fashion brands. A limitation of this study, however, lies in its focus on luxury brands from only one product category — fashion — with high status relevance. Thus, it remains unclear which effects can be expected for established brands from other product categories.

The studies by Van Dijk et al. (2014) and Nishikawa et al. (2017) constitute further relevant contributions, as they also tested real brands. Van Dijk et al. (2014) picked tapas as a product category. They found a significant positive effect on behavioural intentions for the CE strategy if the respondents were provided with additional material proving that customer empowerment had taken place. However, this effect was attenuated if no proof was given. Furthermore, results indicated a gender difference: For women, customer empowerment without proof actually produced slightly negative effects on behavioural intentions. The authors explained this result with a more critical examination of the product and an increased sensibility to missing information, which in turn negatively affects consumers' views of the brand's sincerity and thus makes the consumer less inclined to buy the product. Nishikawa et al. (2017) examined snacks and electronics (i.e., a rather simple security buzzer) by the brand Muji and found that including the reference "customer-ideated" had a positive effect on actual sales, comparing two 
products by the same brand. However, their results, as well as those presented in Van Dijk et al. (2014) for the product category tapas, can hardly be considered generalisable to other product categories, like, for instance, more complex technological products, in which brands are well established and strongly influence consumers' choices, or for the competition between two well-established brands.

Altogether, we conclude that the empirical evidence for the effect of customer empowerment on perceived innovation ability and behavioural intentions for established brands is very limited.

\section{Effects of the empowerment strategy tested}

Table 2 also indicates that only the studies by Fuchs and Schreier (2011) compared all of the empowerment strategies mentioned above. The authors tested products from three different categories, T-shirts, furniture, and bicycles, and found that all three empowerment strategies (SE, CE, and FE) increased the perceived consumer orientation in all product categories. On average, non-participating consumers anticipated that a firm that empowers its customers is more capable of addressing consumers' needs than a company that does not employ an empowerment strategy. While the FE strategy led to a higher score for consumer orientation than the SE and the CE strategies in study 1, these differences were not statistically significant. Furthermore, Fuchs and Schreier found that empowering companies were perceived more favourably and that their products induced more positive behavioural intentions for two out of three tested product categories (in their study 2): consumers indicated greater willingness to buy from, be loyal to, recommend, and commit to companies that empowered their customers through any of the three strategies. The authors kept the brands blind for the products furniture and bicycles and tested the brand Threadless for T-shirts. However, none of the respondents expressed that they had heard of the company Threadless before, so, in fact, the brand was unknown.

Fuchs et al. (2013) have also tested (in an add-on study mentioned in their concluding section) whether involving customers in only the selection of the products leads to a positive attitudinal response of non-involved consumers. The authors observed that involving customers in only the selection decreased the demand for high prestige luxury brands but increased demand for non-luxury brands. As Fuchs et al. examined only the SE strategy in their add-on study, without testing the potential differences between strategies, their findings cannot be used to derive hypotheses about potential differences between empowerment strategies.

In line with Gemser and Perks (2015), we feel that all aspects of customer empowerment (empowering to select as well as to create products) are important 
when operationalising or determining the effect of consumer empowerment. There is only a limited number of empirical studies testing differences between empowerment strategies. We accordingly strive to explicitly test whether the alternative customer empowerment strategies positively influence perceived innovation ability and behavioural intentions.

\section{Research Hypotheses}

The starting point for our research is the theoretical framework established by Schreier et al. (2012) on the effects of empowering customers on the perceptions and behavioural intentions of non-participating consumers towards well-established brands. This framework suggests that positive effects on behavioural intentions are positively mediated by perceived innovation ability. The underlying idea is that consumers perceive products created by customers as being more innovative and the increased perceived innovation ability of the company then increases the consumers' intentions to prefer, buy, and recommend the respective products. The research framework described and proposed by Schreier et al. is depicted in Fig. 1. In line with it, our empirical study aims not only at testing the significance of the direct effect of the empowerment strategy on behavioural intentions but also at investigating the mediation effect of the perceived innovation ability.

\section{The effect of customer empowerment on the perception of innovation ability}

The first qualitative study by Schreier et al. (2012) provides several arguments why consumers could perceive designs by customers as being more innovative. Interestingly, Schreier et al. only tested innovations created by customers, but not those selected by customers. Still, their four arguments also hold for the SE strategy. First, a large number of customers selecting the best idea might help identify the ideas with the best market potential. Second, a greater diversity of people involved in the process might also help select better products because it

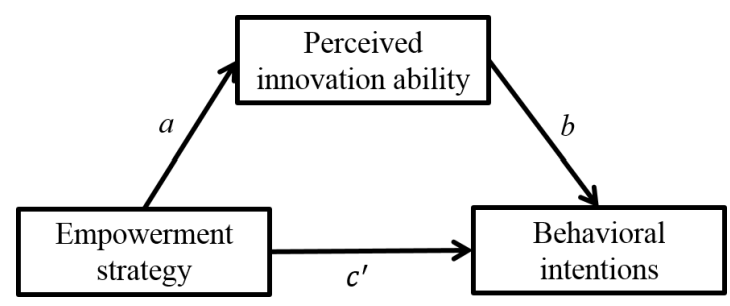

Fig. 1. Schreier et al.'s framework of perceived innovation ability mediating the effect of the empowerment strategy on behavioural intentions. 
guarantees that the products do not appeal only to a small number of "elite designers" but to a broader group of consumers. Third, consumers might also trust the choices of customers more, as many consumers will have experience with recommendations from online reviews and therefore frequently use a similar source of information before making their own purchase decisions. Fourth, customers may be less reluctant to propose creative solutions than in-house designers may be, as they do not have to care about the company's overall profile.

Schreier et al. (2012) found a positive effect of customer empowerment on perceived innovation ability for most product categories when not explicitly emphasising the complexity of the product category. In our scenario, we assume that customers only influence design aspects of the product. Consequently, the customer empowerment process is as simple as in the scenarios used by Schreier et al. for low complexity products. Given that the above four arguments also apply to innovations selected by customers, we hypothesise that both the SE and the CE strategy as well as the combination thereof (FE) should increase the perceived innovation ability of the firm. There is no contrary empirical evidence in the literature concerning significant differences between the empowerment strategies. In all, the below three research sub-hypotheses are in line with earlier empirical findings for fictitious brands and less complex products (see Fuchs and Schreier, 2011; Schreier et al., 2012).

H1a/b/c: Labelling a product of a well-established brand as (a) selected, (b) created, or $(c)$ created and selected by customers (versus by the company) increases the perceived innovation ability of the brand.

\section{The effect of customer empowerment on behavioural intentions}

Fuchs and Schreier (2011) and Schreier et al. (2012) found that products from companies that empower their customers induce more positive behavioural intentions for most tested product categories, but they did not test well-known consumer brands and used primarily blinded brand information in their studies. The study by Fuchs et al. (2013) then demonstrated potential negative effects on behavioural intentions (measured as consumer demand in these studies) for luxury fashion brands with high status (as opposed to mainstream products and products with a low status). With respect to the latter findings, we could hypothesise that due to a potentially higher status relevance of technology brands, customer empowerment strategies could also be negatively perceived and therefore decrease consumers' behavioural intentions (as was the case for the high status fashion brands). However, the fact that technology brands are now mainstream brands could also mean that consumers generally honour products created by customers, 
which is why a total positive effect on non-participating consumers' purchasing intentions is plausible. As mainstream technology brands are supposed to be of lower status-relevance than luxury fashion, we assume a net positive effect on behavioural intentions for all empowerment strategies.

Moreover, the results from study 2 published by Fuchs and Schreier (2011) suggest that the potential effect of customer empowerment on behavioural intentions might be slightly stronger for the FE strategy than for the CE and SE strategies. Differences between strategies, however, were not statistically significant and have only been tested in this one empirical paper. We therefore do not hypothesise that we will find significant differences between strategies. The following research hypotheses will be tested:

H2a/b/c: Labelling a product of a well-established brand as (a) selected, (b) created, or (c) created and selected by customers (versus by the company) increases the non-participating consumers' intentions to recommend, buy, or prefer products of that brand (behavioural intentions).

\section{Perceived innovation ability as a mediator}

Fuchs and Schreier (2011) showed that the perceived innovation ability positively mediates the effect of the empowerment strategy on behavioural intentions. In line with these findings, Schreier et al. (2012) also found a positive mediation effect for less complex product categories. We thus hypothesise - in line with the research framework depicted in Fig. 1 - that there is a positive mediation effect for all three empowerment strategies SE, CE, and FE $(\mathrm{a} / \mathrm{b} / \mathrm{c})$. Again, there is no contrary empirical evidence in the literature concerning differences between the empowerment strategies:

$\mathbf{H 3 a} / \mathbf{b} / \mathbf{c}:$ The effect of labelling a product of a well-established brand as (a) selected, (b) created, or (c) created and selected by customers (versus by the company) on the non-participating consumers' intentions to recommend, buy, or prefer products of that brand (behavioural intentions) is positively mediated by the perceived innovation ability of the brand.

\section{Study Design}

To study the mediating effects of consumer empowerment on customer intentions within the described framework, we selected two well-known consumer technology brands (Apple and Nokia) and chose smartphones as an interesting and as-yet untested product category. We examined two brands in order to exclude or 
attenuate potential brand-specific effects, such as the status of the respective brand. While Nokia smartphones, such as the Lumia phone, are now sold by the brand Microsoft, the studies herein were conducted in 2014, when Nokia still sold the smartphone Lumia under the well-established brand name Nokia.

The study design included an initial evaluation of whether survey respondents (selected as described below) had ever used a smartphone and knew the respective brands (either Apple or Nokia). We also asked respondents whether they owned products of the respective brand. Afterwards, all respondents read identical basic information about the technology company Apple/Nokia introducing it as a cell phone manufacturer. The text on this screen was the same except for the name of the respective brand. Respondents then received group-specific information about the company's design approach in the new product development process. In the SE and $\mathrm{ZE}$ conditions, the participants were told that the company instructed its chief designer to develop new designs. In the $\mathrm{CE}$ and $\mathrm{FE}$ conditions, they were told that the company has called on their customers to develop new designs. Afterwards, respondents in the $\mathrm{CE}$ and $\mathrm{ZE}$ conditions received the information that the company selects the four best prototypes, which then go into series production, whereas those in the SE and FE conditions were told that this decision is arrived at by asking customers for their input. The manipulation was identical for Apple and Nokia. In all, we think that we created a very realistic manipulation scenario by telling the respondents that customers were involved in the selection and/or creation of design elements (and not in the more technologically complex aspects of smartphones) and taking an actual well-established brand as opposed to an unknown generic brand.

\section{Measures}

Respondents were then questioned about their behavioural intentions towards the company's smartphones, i.e., their self-stated intentions of recommending, purchasing, and preferring the company's smartphones over those of other brands in the future. All items were measured on 9-point Likert-type scales. Subsequently, respondents were asked how they perceive the company's innovation ability. We extended the three-item scale previously used by Schreier et al. (2012) by one additional item in order to include the perceived degree of customer-orientation. The participants in our survey had to rate the company's approach, based on the information provided to them, towards developing new products with regard to innovativeness, interestingness, newness, and the degree of customer orientation. The constructs and items used to measure both the behavioural intentions and the perceived innovation ability are shown in Table A.1. 
Our questionnaire contained additional items regarding the respondents' previous involvement in innovation processes and media usage. The analysis of these variables, however, goes beyond the focus of this paper. The survey ended with socio-demographic questions.

Finally, as a manipulation check, we asked respondents the following question: "On the basis of the information you have, how would you rate the following statement? The company [Apple/Nokia] tries to involve their customers." Answers were again chosen on a 9-point Likert-type scale $(1=$ "does not apply at all," and $9=$ "applies completely"). Moreover, as a second check of whether respondents remembered the information given in the manipulation, we also asked respondents "According to the scenario presented at the beginning of the survey, who creates and selects new smartphone designs for [Apple/Nokia]?" We counted the number of correct answers in every condition.

\section{Samples}

We used the largest crowdsourcing platform, Amazon's Mechanical Turk (MTurk) website, to recruit respondents. A concern that is often raised with regard to MTurk is that lower payment may lead to lower quality work. We paid $\$ 0.50$ for every completed survey and announced that the survey was supposed to take $15 \mathrm{~min}$. The average survey time was $6.8 \mathrm{~min}$ with a standard deviation of $2.9 \mathrm{~min}$. Of the respondents, $98.6 \%$ were able to finish the survey within the suggested $15 \mathrm{~min}$. The promised hourly average wage therefore was $\$ 2 /$ hour. The average wage based on the actual time it took to finish the survey was $\$ 4.55 /$ hour. Apart from the question of whether such payment is fair for the workers (although it is higher than for many other tasks on MTurk), higher compensation rates seem to have no (or only a small) effect on data quality. Buhrmester et al. (2011) as well as Mason and Watts (2009), for instance, found that higher compensation rates decreased the amount of time it took to recruit respondents but did not influence the quality of the gathered data.

As a means to select reliable MTurk workers and, thus, to ensure high data quality, we used the HIT statistics to limit access to our survey in two respects. Firstly, participants in our survey had to have an approval rate of $95 \%$ or higher from previous tasks and, secondly, they had to have more than 1,000 approved HITs from previous projects.

While MTurk provides data quickly and for relatively low cost, responses need to be carefully validated. We therefore redirected subjects to our own server, which gave us control with respect to quality assurance. We checked for WorkerIDs to make sure that no workers submitted multiple entries. In order to filter out spammers and bots we also looked at the pattern of responses and response times. 
Furthermore, we added control questions and excluded workers who gave incorrect answers to them. About 7\% of the respondents (124 of 1,665 respondents) had to be discarded from the final dataset on this account. Consequently, 1,541 respondents passed the data quality check.

The most serious disadvantage of using MTurk data is that the sample is not representative of any geographical area or population segment. However, MTurk provides a diverse subject pool that can broaden the validity of studies beyond the commonly utilised undergraduate population (Mason and Suri, 2012). Buhrmester et al. (2011) found that MTurk data is at least as reliable as convenience samples gathered by means of traditional approaches and that generated MTurk samples are even slightly more demographically diverse than standard Internet samples and significantly more diverse than typical American college samples. As for most of the preceding studies listed in Table 2 that rely on either student samples (e.g., Fuchs and Schreier, 2011; Schreier et al., 2012; Fuchs et al., 2013) or on MTurk data (e.g., Dahl et al., 2013), issues related to selection and generalisability may exist in our study as well. We compared our MTurk samples with the ANES web sample, which is a population-based sample that, with the use of weights, is representative of the U.S. population (see Levay et al., 2016). As can be concluded from Table A.2 in the appendix, our samples are very similar to the MTurk sample of Levay et al. (2016). The average age in all MTurk samples is considerably lower than the age in the ANES web sample. Moreover, the MTurk samples contain more males than females as compared to the ANES web sample. In line with Levay et al. (2016), we also find that MTurkers have a lower income, but a higher level of education than those in the ANES web sample. The household size in our MTurk samples is smaller than the average household size in the ANES web sample. In all, as in almost all empirical social science studies, our samples are biased by potential self-selection effects of the MTurk platform. These issues, however, do not undermine the usefulness of the samples for investigating our research question (Horton et al., 2011), but only the generalisability of our findings for the U.S. population.

Participants were randomly allocated to eight experimental conditions (two brands $\times$ four empowerment strategies) in a between-subject design. The remaining sample of 1,541 respondents (Apple: 795; Nokia 746) were asked

Table 3. Participants in the main study by empowerment condition.

\begin{tabular}{lccccc}
\hline & ZE & SE & CE & FE & Total \\
\hline Apple & 200 & 181 & 209 & 186 & 776 \\
Nokia & 172 & 190 & 181 & 185 & 728 \\
\hline
\end{tabular}


whether they knew the brand Apple/Nokia. Those who had never heard of the respective brand were discarded, leaving a final dataset of 776 respondents for Apple and 728 respondents for Nokia (an overview of their distribution among the experimental conditions is given in Table 3). Since the share of respondents who did not know the respective brands was nearly identical for both brands (2.4\%), differences in brand awareness, which could have influenced the comparability of the sub-samples, was ruled out.

\section{Results and Discussion}

\section{Structural equivalence of the sub-samples}

To test the structural equivalence of the eight experimental groups, we performed $F$-tests and $\chi^{2}$-homogeneity tests using the socio-demographic variables age, gender, household size, and income (see Table A.3). We did not find statistical differences between the four empowerment strategies for either Apple or Nokia for any of the socio-demographic variables tested and conclude that the eight subsamples are structurally equivalent.

\section{Manipulation check}

To confirm that the conditions including some form of customer-empowerment (i.e., the SE, CE, and FE strategies) are associated with higher customer involvement than the $\mathrm{ZE}$ condition, we submitted the perceived customer involvement to analysis of variance (ANOVA). As expected, respondents rated the degree of customer involvement as being significantly higher in the $\mathrm{SE}, \mathrm{CE}$, and $\mathrm{FE}$ condition than in the ZE condition (Apple: $M_{\mathrm{ZE}}=5.51, M_{\mathrm{CE}}=7.75, M_{\mathrm{SE}}=7.56, M_{\mathrm{FE}}=7.75, \mathrm{~F}(3)=$ 78.74, $p<0.01$; Nokia: $M_{\mathrm{ZE}}=4.80, M_{\mathrm{CE}}=7.96, M_{\mathrm{SE}}=7.97, M_{\mathrm{FE}}=8.04, \mathrm{~F}$ $(3)=185.72, p<0.01)$. Additionally, we measured how many respondents correctly remembered who creates and selects new smartphone designs for the respective brand at the end of the questionnaire. The percentage of respondents correctly remembering that information was high in all experimental conditions (Apple: $\mathrm{ZE}=92.0 \%, \mathrm{CE}=90.9 \%, \mathrm{SE}=91.2 \%, \mathrm{FE}=96.2 \%$; Nokia: $\mathrm{ZE}=91.9 \%$, $\mathrm{CE}=93.9 \%, \mathrm{SE}=95.3 \%, \mathrm{FE}=96.8 \%)$. We therefore conclude that our manipulation worked as intended. Because it is a manipulation check question, we did not exclude respondents based on not correctly answering this question.

\section{Reliability of the constructs}

We tested the reliability of our constructs perceived innovation ability and behavioural intentions for all eight experimental conditions. As Schreier et al. 
Table 4. Reliability of constructs used in the main study - variance explained by the first factor and Cronbach's alpha.

\begin{tabular}{lcccccc}
\hline Measure & Brand & Reliability criterion & ZE & SE & CE & FE \\
\hline Perceived innovation ability & \multirow{2}{*}{ Apple } & Variance explained & $85.44 \%$ & $74.18 \%$ & $74.23 \%$ & $75.61 \%$ \\
& & Cronbach's alpha & 0.94 & 0.88 & 0.88 & 0.89 \\
& \multirow{2}{*}{ Nokia } & Variance explained & $85.09 \%$ & $72.84 \%$ & $79.30 \%$ & $74.05 \%$ \\
& & Cronbach's alpha & 0.94 & 0.87 & 0.91 & 0.88 \\
Behavioural intentions & \multirow{2}{*}{ Apple } & Variance explained & $88.96 \%$ & $89.58 \%$ & $89.96 \%$ & $88.97 \%$ \\
& & Cronbach's alpha & 0.93 & 0.94 & 0.94 & 0.94 \\
& \multirow{2}{*}{ Nokia } & Variance explained & $86.29 \%$ & $87.66 \%$ & $84.50 \%$ & $87.78 \%$ \\
& & Cronbach's alpha & 0.92 & 0.93 & 0.91 & 0.93 \\
\hline
\end{tabular}

(2012) did, we ran separate exploratory factor analyses and tested whether the items load on a single factor. Table 4 shows the variance explained by the first factor from a factor analysis as well as the respective Cronbach's alphas.

A Cronbach's alpha higher than 0.8 (most often even higher than 0.9) is achieved in all sub-samples for both constructs. We therefore conclude that both scales are highly reliable. Moreover, the reliability level is similar to that in previous studies by Schreier et al. (2012). It is important to note that, because Schreier et al. found no significant order effects, the order of the measures for innovation ability and behavioural intentions was not randomised.

\section{Discriminant validity}

As a preliminary analysis, we also evaluated the discriminant validity of the two latent constructs used in our study, that is, perceived innovation ability and behavioural intentions. Following the literature (e.g., Zhao et al., 2010), we conducted several confirmatory factor analyses. We compared the fit of a two-factor model with the fit of a one-factor model in order to test for a potential common method bias. The fit of the two-factor model is significantly better than that of the one-factor model for both tested brands (Apple: $\Delta \chi^{2}=484.82-91.08=393.74$, df $=14-1=1, p<0.01$; Nokia: $\Delta \chi^{2}=359.40-99.01=260.39$, df $=14-$ $13=1, p<0.01)$.

As a complementary test, we compared the average variance extracted (AVE) of both constructs with the correlation coefficient of the two constructs. We found that the AVE values are substantially higher than the respective correlation coefficients (Apple: AVE $=0.79>r=0.62$; Nokia: AVE $=0.78>r=0.55$ ) (see Fornell and Larcker, 1981). Together, the above two results provide strong evidence for discriminant validity. All factor loadings exceeded 0.80 and were 
significant $(p<0.01)$. Moreover, the AVEs were higher than the recommended threshold of 0.50 (Fornell and Larcker, 1981).

\section{Differences concerning perceived innovation ability and behavioural intentions}

As can be seen in Table 5, for both brands, the innovation ability is perceived as significantly higher in all experimental conditions that included some form of customer empowerment ( $\mathrm{SE}, \mathrm{CE}, \mathrm{FE}$ ) compared to the condition in which customers were not empowered (ZE; the $p$-values listed in Table 5, along with results from pairwise $t$-tests comparing the respective empowerment strategies with the $\mathrm{ZE}$ strategy). These results therefore confirm $\mathrm{H} 1 \mathrm{a} / \mathrm{b} / \mathrm{c}$ for both brands. Interestingly, Apple is perceived as having a significantly higher innovation ability than Nokia (mean (SD) Apple $=7.05$ (1.85); mean (SD) Nokia $=6.77(1.95) ; t=2.88$; $p<0.01)$. We explain this result with the fact that Apple introduced the iPhone, which subsequently changed the structure of the whole cell phone market. This transformation might have contributed to a higher perceived innovation ability for Apple.

To test whether labelling a brand's smartphone as "selected," "created," or "created and selected," by customers significantly changes the non-participating consumers' behavioural intentions, we again performed pairwise $t$-tests. For both brands, the CE and FE conditions had no significant effect on behavioural intentions. These two empowerment strategies, which include customer empowerment in the creation phase, apparently do not lead to more positive behavioural intentions. Taken together, the empirical results do not confirm a positive effect on behavioural intentions for the $\mathrm{CE}$ or FE strategy $(\mathrm{H} 2 \mathrm{~b} / \mathrm{c})$. However, the behavioural intentions were higher in the SE condition than under ZE for both brands.

Table 5. Comparison of perceived innovation ability and behavioural intentions.

\begin{tabular}{lcccccc}
\hline Measure & Brand & & ZE & SE & CE & FE \\
\hline $\begin{array}{l}\text { Perceived innovation } \\
\text { ability (H1) }\end{array}$ & Apple & Mean (SD) & $5.87(2.28)$ & $7.46(1.37)$ & $7.47(1.51)$ & $7.44(1.49)$ \\
& & $p$-value & & $<0.01$ & $<0.01$ & $<0.01$ \\
& Nokia & Mean (D) & $5.09(2.24)$ & $7.30(1.46)$ & $7.29(1.57)$ & $7.26(1.49)$ \\
& & $p$-value & & $<0.01$ & $<0.01$ & $<0.01$ \\
Behavioural intentions & Apple & Mean (SD) & $6.72(1.94)$ & $6.99(1.91)$ & $6.86(1.99)$ & $6.67(1.96)$ \\
$(H 2)$ & & $p$-value & & 0.19 & 0.48 & 0.80 \\
& \multirow{2}{*}{ Nokia } & Mean (D) & $5.99(1.84)$ & $6.63(1.55)$ & $6.01(1.70)$ & $6.01(1.75)$ \\
& & $p$-value & & $<0.01$ & 0.90 & 0.92 \\
\hline
\end{tabular}


The difference, nevertheless, is only significant for the brand Nokia, while it is close to significance for Apple. Hypothesis $\mathrm{H} 2 \mathrm{a}$ is therefore only partly confirmed.

\section{Perceived innovation ability as a mediator}

The empirical results for $\mathrm{H} 1$ and $\mathrm{H} 2$ raise an interesting issue: For both brands, the empowerment of customers strongly increases the consumers' perception of the brand's innovation ability. However, we also observe that only in the SE condition for Nokia were the consumers' behavioural intentions higher than under ZE. The question therefore arises whether the perceived innovation ability actually mediates the effect of the empowerment strategy on behavioural intentions for each of the three forms of customer empowerment $(\mathrm{H} 3 \mathrm{a} / \mathrm{b} / \mathrm{c})$. To explore this, we ran separate mediation tests in line with the framework depicted in Fig. 1 and performed bootstrap analyses with bias-corrected confidence estimates (Preacher and Hayes, 2008); the 95\% confidence interval of the indirect effects was obtained with 5,000 bootstrap resamples.

The results of the mediation analyses confirm the mediating role of perceived innovation ability in the relation between empowerment strategy and behavioural intentions. Tables 6 and 7 summarise the results of the six separate bootstrap analyses comparing each of the empowerment strategies SE, CE, and FE with the benchmark condition ZE.

For Nokia, we obtain a significant total effect only in the SE condition, but not in the $\mathrm{CE}$ and $\mathrm{FE}$ condition. In all three conditions, empowering customers to select and/or create designs increases the perceived innovation ability (a), which in turn positively affects the consumers' behavioural intentions $(b)$. Thus, the indirect effect $(a \cdot b)$ is positive and significant for all three empowerment strategies. However, we also find that customer empowerment has a significant negative direct effect on behavioural intentions (c'). This effect is less strong under the SE

Table 6. Nokia - Direct, indirect, and total effects of the empowerment strategies (ES) on behavioural intentions (BI) and mediation by perceived innovation ability (PIA) when compared with the baseline (ZE).

\begin{tabular}{|c|c|c|c|}
\hline Empowerment strategy & SE & $\mathrm{CE}$ & $\mathrm{FE}$ \\
\hline Total effect ES $\rightarrow$ BI (c) & $0.19^{* * *}(0.05)$ & $(0.05)$ & $(0.05)$ \\
\hline Direct effect ES $\rightarrow$ BI (c') & $-0.19^{* * *}(0.05)$ & $-0.37^{* * *}(0.05)$ & $-0.36^{* * *}(0.05)$ \\
\hline Indirect effect $\mathrm{ES} \rightarrow \mathrm{BI}(\mathrm{a} \cdot \mathrm{b})$ & $0.37^{* * *}(0.04)$ & $0.38^{* * *}(0.04)$ & $0.36^{* * *}(0.04)$ \\
\hline Effect ES $\rightarrow$ PIA (a) & $0.51^{* * *}(0.05)$ & $0.50^{* * *}(0.05)$ & $0.50^{* * *}(0.05)$ \\
\hline Effect PIA $\rightarrow$ BI (b) & $0.73^{* * *}(0.05)$ & $0.77^{* * *}(0.05)$ & $0.72^{* * *}(0.05)$ \\
\hline
\end{tabular}

Note: $\beta(\operatorname{std}(\beta))$ values, ${ }^{* * *}$ indicates significance at $\alpha=0.01,{ }^{* *}$ indicates significance at $\alpha=0.05,{ }^{*}$ indicates significance at $\alpha=0.10$. 
Table 7. Apple - Direct, indirect, and total effects of the empowerment strategies (ES) on behavioural intentions (BI) and mediation by perceived innovation ability (PIA) when compared with the baseline (ZE).

\begin{tabular}{|c|c|c|c|}
\hline Empowerment strategy & SE & $\mathrm{CE}$ & FE \\
\hline Total effect ES $\rightarrow$ BI (c) & $(0.05)$ & $(0.05)$ & $(0.05)$ \\
\hline Direct effect ES $\rightarrow$ BI (c') & $-0.20^{* * *}(0.04)$ & $-0.24^{* * *}(0.04)$ & $-0.29^{* * *}(0.04)$ \\
\hline Indirect effect $\mathrm{ES} \rightarrow \mathrm{BI}(\mathrm{a} \cdot \mathrm{b})$ & $0.27^{* * *}(0.04)$ & $0.28^{* * *}(0.04)$ & $0.28^{* * *}(0.04)$ \\
\hline Effect ES $\rightarrow$ PIA (a) & $0.39^{* * *}(0.05)$ & $0.39^{* * *}(0.05)$ & $0.38^{* * *}(0.05)$ \\
\hline Effect PIA $\rightarrow$ BI (b) & $0.70^{* * *}(0.04)$ & $0.73^{* * *}(0.04)$ & $0.75^{* * *}(0.04)$ \\
\hline
\end{tabular}

Note: $\beta(\operatorname{std}(\beta))$ values, ${ }^{* * *}$ indicates significance at $\alpha=0.01,{ }^{* *}$ indicates significance at $\alpha=0.05,{ }^{*}$ indicates significance at $\alpha=0.10$.

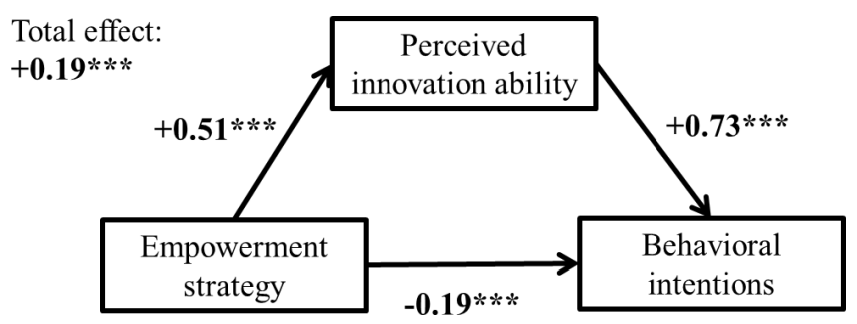

Fig. 2. SE condition for the brand Nokia: Perceived innovation ability mediates the positive effect of the empowerment strategy on behavioural intentions.

strategy, which leads to a significant positive total effect (c) in this condition (see Fig. 2). For the CE and FE condition, the direct negative effect is as strong as the indirect positive effect. As a result, we do not see that customer empowerment significantly increases the consumers' behavioural intentions in these two conditions.

For Apple, we recognise similar patterns in Table 7. The total effects are not significant for any of the empowerment strategies, but the perceived innovation ability operates as a positive mediator, influencing the relationship between the empowerment strategy and the behavioural intentions in all three conditions (SE, $\mathrm{CE}$, and $\mathrm{FE}$ ).

Such findings for the mediation effect are described in the literature as "competitive mediation" or "inconsistent mediation" and occur if an indirect effect $(a \cdot b)$ and a direct effect (c') are of opposite signs. Thus, "it may well be possible to establish an indirect effect despite no total effect" (Zhao et al., 2010, p. 200). This is the case in our empirical study, as we find a significant mediation of the factor perceived innovation ability while finding no total effect on behavioural intentions for all strategies tested (except for the SE strategy for Nokia). Furthermore, the significant direct effect points to a "possible existence of some 
omitted second mediator that can be pursued in future research" (p. 201). We have so far not included other factors that could be used as further mediators in our model. Accordingly, additional empirical studies are needed in order to fully explain these effects.

Altogether, our empirical results mirror previous findings showing a positive mediation effect for perceived innovation ability, confirming hypothesis $\mathrm{H} 3$ for all tested empowerment strategies $(\mathrm{H} 3 \mathrm{a} / \mathrm{b} / \mathrm{c})$.

\section{Control for the influence of socio-demographic variables and product ownership}

It is likely that other socio-demographic characteristics, such as age and income, as well as past purchase behaviour revealed by product ownership also affect consumers' behavioural intentions. Older respondents, for example, might evaluate the empowerment strategies more positively than younger respondents just because the empowerment-idea is new to them. The influence of socio-demographics, however, is not tested and discussed in the literature. We therefore decided to include the socio-demographic variables age, household size, income, education, and product ownership as control variables in the mediation analysis. Tables 8 and 9 show the results for Nokia and Apple, respectively.

First, it is important to explore whether the results of the mediation analysis change substantially once we include the control variables in the analysis. As can

Table 8. Nokia - Direct, indirect, and total effects of the empowerment strategies (ES) on behavioural intentions (BI) and mediation by perceived innovation ability (PIA) when compared with the baseline (ZE) when including control variables.

\begin{tabular}{|c|c|c|c|c|c|}
\hline \multirow{2}{*}{$\frac{\text { Empowerment strategy }}{\text { Total effect ES } \rightarrow \text { BI (c) }}$} & \multirow{2}{*}{$\frac{\mathrm{SE}}{0.19^{* * *}(0.05)}$} & \multicolumn{2}{|c|}{$\mathrm{CE}$} & \multicolumn{2}{|c|}{$\mathrm{FE}$} \\
\hline & & 0.02 & $(0.05)$ & 0.03 & $(0.05)$ \\
\hline Direct effect ES $\rightarrow$ BI (c') & $-0.14^{* * *}(0.05)$ & $-0.32^{* * *}$ & $(0.05)$ & $-0.29^{* * *}$ & $(0.04)$ \\
\hline Indirect effect $\mathrm{ES} \rightarrow \mathrm{BI}(\mathrm{a} \cdot \mathrm{b})$ & $0.33^{* * *}(0.04)$ & $0.33^{* * *}$ & $(0.04)$ & $0.32^{* * *}$ & $(0.04)$ \\
\hline Effect ES $\rightarrow$ PIA (a) & $0.50^{* * *}(0.05)$ & $0.49^{* * *}$ & $(0.05)$ & $0.51^{* * *}$ & $(0.05)$ \\
\hline Effect PIA $\rightarrow$ BI (b) & $0.65^{* * *}(0.05)$ & $0.68^{* * *}$ & $(0.05)$ & $0.64^{* * *}$ & $(0.05)$ \\
\hline \multicolumn{6}{|l|}{ Control variables } \\
\hline Age & $0.11^{* *}(0.05)$ & 0.06 & $(0.05)$ & $0.11^{* *}$ & $(0.05)$ \\
\hline Household size & $0.15^{* * *}(0.05)$ & $0.25^{* * *}$ & $(0.05)$ & $0.18^{* * *}$ & $(0.05)$ \\
\hline Income & $-0.17^{* * *}(0.05)$ & $-0.18^{* * *}$ & $(0.05)$ & $-0.14^{* * *}$ & $(0.05)$ \\
\hline Education & $0.09^{*} \quad(0.05)$ & 0.04 & $(0.05)$ & 0.04 & $(0.05)$ \\
\hline Product ownership & $0.35^{* * *}(0.05)$ & $0.29^{* * *}$ & $(0.05)$ & $0.36^{* * *}$ & $(0.05)$ \\
\hline
\end{tabular}

Note: $\beta(\operatorname{std}(\beta))$ values, ${ }^{* * *}$ indicates significance at $\alpha=0.01,{ }^{* *}$ indicates significance at $\alpha=0.05,{ }^{*}$ indicates significance at $\alpha=0.10$. 
Table 9. Apple - Direct, indirect, and total effects of the empowerment strategies (ES) on behavioural intentions (BI) and mediation by perceived innovation ability (PIA) when compared with the baseline (ZE) when including control variables.

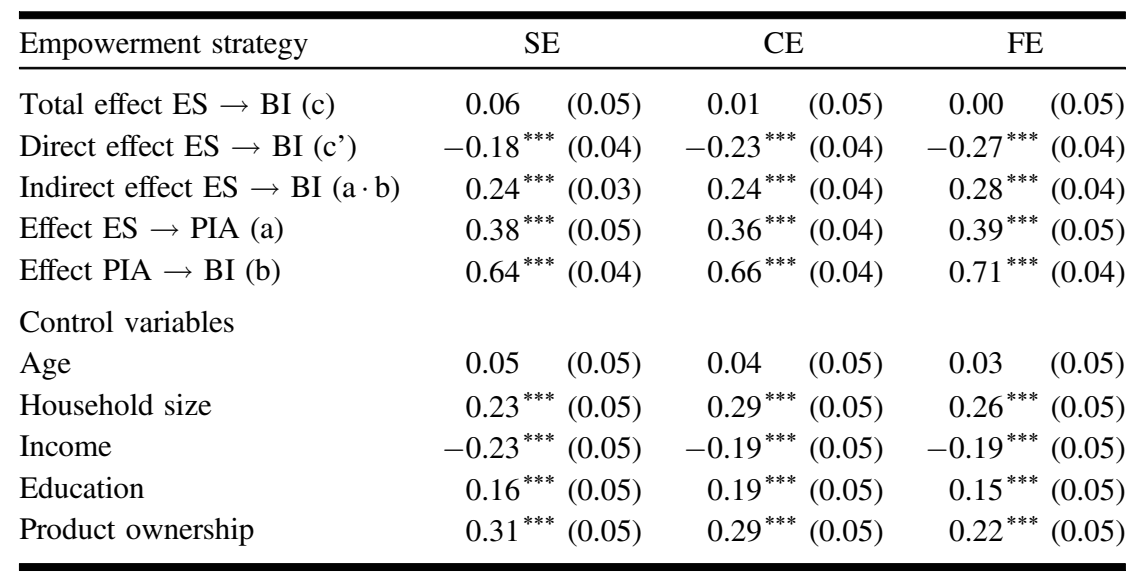

Note: $\beta(\operatorname{std}(\beta))$ values, ${ }^{* * *}$ indicates significance at $\alpha=0.01,{ }^{* *}$ indicates significance at $\alpha=0.05,{ }^{*}$ indicates significance at $\alpha=0.10$.

be seen from Tables 8 and 9, the estimated $\beta$ values are very similar to the ones presented in Tables 6 and 7 and the significance values of the effects do not change at all. We also observe that the effect of perceived innovation ability on behavioural intentions slightly decreases in all of the conditions for both Nokia and Apple, probably because some of the control variables now explain parts of the variance for behavioural intentions, which was previously explained by perceived innovation ability.

Second, it is interesting to examine which of the control variables have a significant effect on behavioural intentions. For both brands, Apple and Nokia, we find that behavioural intentions increase with household size and product ownership, but decrease with income. The result for product ownership makes intuitive sense, because consumers who already own one or several products of the same brand should be more likely to buy products of the same brand. The effects for age, income, and household size are hard to explain, mainly because these variables are highly correlated. For example, older respondents are supposed to have a higher disposable income. We therefore refrain from drawing conclusions at this point and suggest that researchers should investigate the potential differences regarding socio-demographics in future studies.

Third, we interestingly find a difference between Nokia and Apple regarding the influence of education on behavioural intentions. Only for the brand Apple, but not for Nokia, the influence of education on behavioural intentions is significant. 
We think that these results are intuitive because the brand Apple historically has been very popular among well-educated consumers.

\section{Conclusions}

This paper investigates the effects of customer empowerment on non-involved consumers based on the theoretical framework by Schreier et al. (2012). The authors demonstrated that empowering customers not only positively influenced involved customers but also positively influenced non-involved consumers. Their empirical results showed that customer empowerment increased the perceived innovation ability of a firm, which then positively influenced behavioural intentions of non-involved consumers.

The contribution of this paper is twofold. The first contribution lies in testing the theoretical framework in a managerially relevant context, i.e., for real, wellestablished brands. The second contribution is that we test different forms of customer empowerment, that is, customers' involvement in either the creation or selection stage or in both of the stages of product development.

We test two actual well-established brands from the technology market, Apple and Nokia, in our empirical study and find that customer empowerment substantially increases the perceived innovation ability of the companies for all alternative empowerment strategies tested. In particular, we show that customer empowerment can be successfully employed for real brands, thereby expanding the analyses by Schreier et al. (2012) and delivering implications that are relevant to actual branding decisions for products of an existing technology brand. This positive effect on perceived innovation ability, per se, seems to be a positive outcome of empowering customers. As Kunz et al. (2011) have shown, increased perceived innovation ability can positively influence consumer loyalty, even if it might not influence behavioural intentions directly. In our study, the perceived innovation ability positively mediates the effect that the customer empowerment strategy has on behavioural intentions in all conditions tested. Nevertheless, only for the brand Nokia we find that, in total, labelling products as selected by customers has a positive effect on behavioural intentions. As the mediation analysis reveals, it is likely that a second, as yet unknown, mediator influences the effect of customer empowerment on behavioural intentions. An important finding of our study, therefore, is the strong indication of the existence of this second mediator, although we currently cannot identify this mediator with the data we have.

The comparison of all three empowerment strategies shows the following: Only the SE strategy increases non-involved consumers' behavioural intentions. This effect is significant for the brand Nokia and close to significant for the brand 
Apple. For the CE and FE strategy, we do not find positive or negative effects for either brand. These findings have direct managerial implications. They indicate that non-involved consumers honour the idea of empowering customers in the selection stage but not in the creation stage of the new product development process. Our empirical results therefore suggest that customers should be empowered at later stages of the new product development process for wellestablished brands, for instance, by letting customers vote on available product concepts designed by the company. The practical implication is that companies can reduce the potential risk of customer empowerment by focussing on the selection part of the process.

Our study is limited in that we have focussed on only two technology brands, Apple and Nokia, and have intentionally restricted the empirical scenario to involving customers in the process of creating or selecting a new smartphone design. Additional well-established brands and different customer empowerment scenarios focussing on different product characteristics should be tested in future studies. A second limitation is that we have tested only one product category, smartphones. The question arises whether our findings also hold for established brands in other product categories. Future research in this direction is important, as today, customer empowerment seems to be used without clear evidence that it substantially increases perceived company innovation ability and consumer behavioural intentions. A third limitation is that we focus on only two outcome variables, namely perceived innovation ability and behavioural intentions, following the research framework by Schreier et al. (2012). Nevertheless, for companies, further factors besides behavioural intentions might be important reasons for empowering customers. These might, for instance, be consumers' long-term loyalty and positive word-of-mouth. Previous studies have tested the effects of increased customer orientation, which is different from perceived innovation ability, but which might have similar effects (Brady et al., 2001; Voss and Voss, 2000). In our paper, we focus on the potential effects on behavioural intentions of non-involved consumers because increased purchasing intention is the most direct behavioural consequence. A fourth limitation is that we used MTurk samples which are not representative for the U.S. population. While we cannot resolve this limitation, we consider it to be very unlikely that using different samples would change our findings. We think that we can make this strong statement because we have included key socio-demographic variables as control variables in an extended analysis and have seen that the effects remained qualitatively unchanged.

Taking into account the aforementioned limitations, the most important task for future research lies in conducting studies that test well-established brands to validate the practical relevance of the empowerment effect on non-involved consumers. We suggest that longitudinal studies focussed on the formation of the 
perception of firms' innovativeness would be very helpful to better understand this mediator. Moreover, the potential competitive advantage of empowering customers will only persist until the majority of companies has adopted similar strategies. Therefore, the question remains to which extent the perception of innovativeness will change if companies use the customer empowerment approach over several years. A potential wear-out effect seems reasonable, in which consumers may, over the years, perceive empowerment to be less and less innovative. More research is also needed to better understand the potential moderators of the effect. Findings by Schreier et al. (2012), for example, suggest that consumers' general familiarity with customer innovation as well as product involvement might moderate the potential positive effect of empowerment on perceived innovation ability. However, we cannot test these potential moderator effects in our dataset because we measured these constructs after manipulating respondents, i.e., after introducing the respective empowerment approach to the respondents.

We also suggest further extending the theoretical framework developed by Schreier et al. (2012) by including potential effects of social identity as later discussed by Dahl et al. (2014). It is currently not evident whether consumers who feel more similar to participating customers will think that the empowerment process is more or less innovative. The size and direction of the effect might depend on how likely consumers think it is that they are themselves involved in the creation or selection process. Discovering effects based on the similarity of involved customers to non-involved consumers would have important managerial implications; it would enable marketers to focus on certain groups of consumers in the empowerment process or enable them to better market the results of the empowerment process. 


\section{Appendix}

Table A.1. Constructs and items used in the empirical study.

\begin{tabular}{|c|c|}
\hline Construct & Items \\
\hline Behavioural intentions & $\begin{array}{l}\text { 1. Would you recommend a smartphone by the company Apple/Nokia? (I } \\
\text { would definitely not recommend it }[-4] \text {; I would definitely } \\
\text { recommend it }[+4] \text { ) } \\
\text { 2. If you had to buy a smartphone in the future, would you buy one by } \\
\text { Apple/Nokia (I would definitely not buy one by Apple/Nokia [-4]; I } \\
\text { would definitely buy one by Apple/Nokia }[+4] \text { ) } \\
\text { 3. Would you prefer the brand Apple/Nokia in future buying decisions } \\
\text { over other companies which produce smartphones? (I would definitely } \\
\text { not prefer Apple/Nokia in the future [-4]; I would definitely prefer } \\
\text { Apple/Nokia in the future }[+4] \text { ) }\end{array}$ \\
\hline Innovation ability & $\begin{array}{l}\text { What do you think about the approach of the company Apple/Nokia with } \\
\text { respect to how the new products are developed? } \\
\text { 1. I think it is not innovative at all }[-4] \text {; I think it is very innovative }[+4] \\
\text { 2. I think it is not interesting at all }[-4] \text {; I think it is very interesting }[+4] \\
\text { 3. I think it is not customer-oriented at all }[-4] \text {; I think it is very } \\
\text { customer-oriented }[+4] \\
\text { 4. I think it is not new at all [-4]; I think itis very new [+4] }\end{array}$ \\
\hline
\end{tabular}

Table A.2. Socio-demographic characteristics of our samples and comparison with MTurk sample by Levay et al. (2016) and 2012 ANES web sample.

\begin{tabular}{|c|c|c|c|c|}
\hline & $\begin{array}{l}\text { ANES web sample } \\
\quad \text { (according to } \\
\text { Levay et al., 2016) }\end{array}$ & $\begin{array}{c}\text { MTurk sample } \\
\text { (Levay et al., } \\
\text { 2016) }\end{array}$ & $\begin{array}{l}\text { MTurk sample } \\
\text { (Apple - } \\
\text { this paper) }\end{array}$ & $\begin{array}{c}\text { MTurk sample } \\
\text { (Nokia - this } \\
\text { paper) }\end{array}$ \\
\hline $\begin{array}{l}\text { Age (mean number } \\
\text { of years) }\end{array}$ & 47.4 & 31.6 & 33.2 & 33.2 \\
\hline Percent male & $47.9 \%$ & $53.9 \%$ & $58.2 \%$ & $54.8 \%$ \\
\hline Income $^{\mathrm{a}}$ & US\$63,565 & US\$54,257 & US\$52,062 & US $\$ 53,690$ \\
\hline \multicolumn{5}{|l|}{ Education } \\
\hline $\begin{array}{l}\text { - Less than high } \\
\text { school }\end{array}$ & $10.3 \%$ & $1.3 \%$ & $0.8 \%$ & $0.1 \%$ \\
\hline $\begin{array}{c}\text { - High school } \\
\text { credential }\end{array}$ & $29.9 \%$ & $10.0 \%$ & $9.5 \%$ & $8.2 \%$ \\
\hline $\begin{array}{l}\text { - Some post-high } \\
\text { school }\end{array}$ & $30.2 \%$ & $43.8 \%$ & $22.6 \%$ & $35.3 \%$ \\
\hline - Bachelor's degree & $18.7 \%$ & $35.8 \%$ & $47.2 \%$ & $42.3 \%$ \\
\hline - Graduate degree & $10.8 \%$ & $9.1 \%$ & $20.0 \%$ & $13.6 \%$ \\
\hline
\end{tabular}


Table A.2. (Continued)

\begin{tabular}{lcccc}
\hline & $\begin{array}{c}\text { ANES web sample } \\
\text { (according to } \\
\text { Levay et al., 2016) }\end{array}$ & $\begin{array}{c}\text { MTurk sample } \\
\text { (Levay et al., } \\
\text { 2016) }\end{array}$ & $\begin{array}{c}\text { MTurk sample } \\
\text { (Apple }- \\
\text { this paper) }\end{array}$ & $\begin{array}{c}\text { MTurk sample } \\
\text { (Nokia - this } \\
\text { paper) }\end{array}$ \\
\hline $\begin{array}{l}\text { Household size } \\
\text { (average number } \\
\text { of persons in } \\
\text { household) }\end{array}$ & 2.42 & n.a. & 2.87 & 2.77 \\
\hline
\end{tabular}

Note: ${ }^{a}$ Data for ANES sample and own samples reflect income midpoints of categorical income variable that was available.

Table A.3. Test of the structural equivalence of the samples (regarding socio-demographics).

\begin{tabular}{|c|c|c|c|c|c|}
\hline Brand & $\begin{array}{c}\text { Empowerment strategy } \\
\text { [sample size] }\end{array}$ & Mean age (SD) & $\begin{array}{l}\text { Percent } \\
\text { female }\end{array}$ & $\begin{array}{c}\text { Average } \\
\text { household } \\
\text { size (SD) }\end{array}$ & $\begin{array}{c}\text { Income } \\
\text { [in categories] }\end{array}$ \\
\hline \multirow[t]{5}{*}{ Apple } & $\mathrm{ZE}[n=200]$ & $32.90(9.90)$ & $40.0 \%$ & $2.86(1.08)$ & - \\
\hline & $\mathrm{SE}[n=181]$ & $33.51(9.91)$ & $40.2 \%$ & $2.85(1.08)$ & - \\
\hline & $\mathrm{CE}[n=209]$ & 33.27 (10.74) & $38.1 \%$ & $2.99(1.07)$ & - \\
\hline & $\mathrm{FE}[n=186]$ & 33.24 (10.67) & $48.9 \%$ & $2.76(1.13)$ & - \\
\hline & Overall $[n=776]$ & $33.22(10.30)$ & $41.8 \%$ & $2.87(1.13)$ & - \\
\hline \multirow{2}{*}{\multicolumn{2}{|c|}{$\begin{array}{l}\text { Statistical test for difference } \\
\text { between strategies for Apple }\end{array}$}} & $F=0.12$ & $x^{2}=5.38$ & $F=1.47$ & $x^{2}=14.64$ \\
\hline & & $p=0.95$ & $p=0.15$ & $p=0.22$ & $p=0.26$ \\
\hline \multirow[t]{5}{*}{ Nokia } & $\mathrm{ZE}[n=172]$ & $31.85(9.23)$ & $39.0 \%$ & $2.74(1.06)$ & - \\
\hline & $\mathrm{SE}[n=190]$ & $33.22(10.47)$ & $45.9 \%$ & $2.72(1.11)$ & - \\
\hline & $\mathrm{CE}[n=181]$ & $31.64(8.72)$ & $44.2 \%$ & $2.80(1.10)$ & - \\
\hline & $\mathrm{FE}[n=185]$ & $32.93(9.76)$ & $51.4 \%$ & $2.84(1.09)$ & - \\
\hline & Overall $[n=728]$ & $32.43(9.59)$ & $45.2 \%$ & $2.77(1.09)$ & - \\
\hline \multirow{2}{*}{\multicolumn{2}{|c|}{$\begin{array}{l}\text { Statistical test for difference } \\
\text { between strategies for Nokia }\end{array}$}} & $F=1.22$ & $x^{2}=5.64$ & $F=0.49$ & $x^{2}=9.23$ \\
\hline & & $p=0.30$ & $p=0.13$ & $p=0.69$ & $p=0.68$ \\
\hline \multirow{2}{*}{\multicolumn{2}{|c|}{$\begin{array}{l}\text { Statistical test for difference } \\
\text { between Apple and Nokia }\end{array}$}} & $F=2.38$ & $x^{2}=1.81$ & $F=2.85$ & $x^{2}=3.23$ \\
\hline & & $p=0.12$ & $p=0.18$ & $p=0.09$ & $p=0.52$ \\
\hline
\end{tabular}

Comment on Table A.3: When comparing Apple and Nokia, we discover that the average household size is weakly significantly higher among respondents who saw the brand Apple than among those who saw the brand Nokia. Taking into account the alpha inflation problem resulting from multiple testing and given the fact that we therefore should test against an even lower alpha value than $10 \%$ (for weak significance), we consider this weak significance in average household size to be negligible. 


\section{References}

Brady, MK and JJ Cronin (2001). Customer orientation: Effects on customer service and outcome behaviors. Journal of Service Research, 3(3), 241-251.

Buhrmester, M, T Kwang and SD Gosling (2011). Amazon's Mechanical Turk: A new source of inexpensive, yet high-quality, data? Perspectives on Psychological Science, $6(1), 3-5$.

Dahl, DW, C Fuchs and M Schreier (2015). Why and when consumers prefer products of user-driven firms: A social identification account. Management Science, 61(8), 19781988.

Ferraro, R, A Kirmani and T Matherly (2013). Look at me! Look at me! Conspicuous brand usage, self-brand connection, and dilution. Journal of Marketing Research, 50(4), 477-488.

Fornell, C and DF Larcker (1981). Evaluating structural equation models with unobservable variables and measurement error. Journal of Marketing Research, 18(1), 39-50.

Franke, N and F Piller (2004). Value creation by toolkits for user innovation and design: The case of the watch market. Journal of Product Innovation Management, 21(6), 401-415.

Fuchs, C, E Prandelli, M Schreier and DW Dahl (2013). All that is users might not be gold: How labeling products as user designed backfires in the context of luxury fashion brands. Journal of Marketing, 77(5), 75-91.

Fuchs, C and M Schreier (2011). Customer empowerment in new product development. Journal of Product Innovation Management, 28(1), 17-32.

Gemser, G and H Perks (2015). Co-creation with customers: An evolving innovation research field. Journal of Product Innovation Management, 32(5), 660-665.

Horton, JJ, DG Rand and RJ Zeckhauser (2011). The online laboratory: Conducting experiments in a real labor market. Experimental Economics, 14(3), 399-425.

Hoyer, WD, R Chandy, M Dorotic, M Krafft and SS Singh (2010). Consumer cocreation in new product development. Journal of Service Research, 13(3), 283-296.

Jespersen, KR (2011). Online channels and innovation: Are users being empowered and involved? International Journal of Innovation Management, 15(6), 1141-1159.

Kaplan, AM and M Haenlein (2006). Toward a parsimonious definition of traditional and electronic mass customization, Journal of Product Innovation Management, 23(2), 168-182.

Kosonen, M, C Gan, M Vanhala and K Blomqvist (2014). User motivation and knowledge sharing in idea crowdsourcing. International Journal of Innovation Management, 18(5), 1-23.

Kunz, W, B Schmitt and A Meyer (2011). How does perceived firm innovativeness affect the consumer? Journal of Business Research, 64(8), 816-822.

Levay, KE, J Freese and JN Druckman (2016). The demographic and political composition of Mechanical Turk samples. SAGE Open, 6(1), 1-17. 
Mahr, D, A Lievens and V Blazevic (2014). The value of customer cocreated knowledge during the innovation process. Journal of Product Innovation Management, 31(3), 599-615.

Mason, W and S Suri (2012). Conducting behavioral research on Amazon's Mechanical Turk. Behavior Research Methods, 44(1), 1-23.

Mason, W and DJ Watts (2009). Financial incentives and the "performance of crowds". In Proc. ACM SIGKDD Workshop on Human Computation, pp. 77-85, New York: ACM.

Nishikawa, H, M Schreier and S Ogawa (2013). User-generated versus designer-generated products: A performance assessment at Muji. International Journal of Research in Marketing, 30(2), 160-167.

Nishikawa, H, M Schreier, C Fuchs and S Ogawa (2017). The value of marketing crowdsourced new products as such: Evidence from two randomized field experiments. Journal of Marketing Research, forthcoming, http://dx.doi.org/10.1509/ jmr.15.0244.

Poetz, K and M Schreier (2012). The value of crowdcoursing: Can users really compete with professionals in generating new product ideas? Journal of Product Innovation Management, 29(2), 245-256.

Prahalad, C and V Ramaswamy (2000). Co-opting customer competence. Harvard Business Review, 78(1), 79-90.

Preacher, KJ and AF Hayes (2008). Asymptotic and resampling strategies for assessing and comparing indirect effects in multiple mediator models. Behavior Research Methods, 40(3), 879-891.

Ramaswamy, V and F Gouillart (2010). The Power of Co-Creation. New York: Free Press.

Schreier, M, C Fuchs and DW Dahl (2012). The innovation effect of user design: Exploring consumers' innovation perceptions of firms selling products designed by users. Journal of Marketing, 76(5), 18-32.

Van Dijk, J, G Antonides and N Schillewaert (2014). Effects of co-creation claim on consumer brand perceptions and behavioural intentions. International Journal of Consumer Studies, 38(1), 110-118.

Voss, GB and ZG Voss (2000). Strategic orientation and firm performance in an artistic environment. Journal of Marketing, 64(1), 67-83.

Wathieu, L, L Brenner, Z Carmon, A Chattopadhyay, K Wertenbroch, A Drolet, J Gourville, AV Muthukrishnan, N Novemsky, RK Ratner and G Wu (2002). Consumer control and empowerment: A primer. Marketing Letters, 13(3), 297-305.

Zhao, X, JG Lynch and Q Chen (2010). Reconsidering Baron and Kenny: Myths and truths about mediation analysis. Journal of Consumer Research, 37(2), 197-206.

Zipkin, P (2001). The limits of mass customization. Sloan Management Review, 42(3), 81-87. 